\title{
Competition, Cooperation, and Pricing: How Mobile Operators Respond to the Challenge of Over-The-Top
}

\author{
Xiaobing $\mathrm{Xu}^{1}$ \& Rong $\mathrm{Chen}^{1}$ \\ ${ }^{1}$ School of Economics and Management, Tsinghua University, Beijing, China \\ Correspondence: Xiaobing Xu, the Department of Marketing, School of Economics and Management, Tsinghua \\ University, Haidian District, Beijing, China, 100084. E-mail: xuxb.12@sem.tsinghua.edu.cn
}

Received: March 5, $2015 \quad$ Accepted: October 16, $2015 \quad$ Online Published: November 30, 2015
doi:10.5539/ijms.v7n6p1
URL: http://dx.doi.org/10.5539/ijms.v7n6p1

This research was supported by the National Natural Science Foundation of China (No. 71472104 and No. $71172011)$.

\begin{abstract}
Considering the threats from OTT (Over-The-Top) services, this paper examines whether the mobile operator should charge OTT services access fees and how to. By using a dynamic-gaming process, we find that: 1) under non-cooperative strategy, the mobile operator would charge OTT a mobile Internet access fee, which is positively correlated to OTT platform's future commercial value and the price of direct communication service, and negatively correlated to the indirect communication service price. 2) under cooperative strategy, the OTT service price that the joint venture charges end users is negatively correlated to OTT platform's future commercial value. 3) despite choosing cooperative or non-cooperative strategy, the pricing of mobile operator's direct communication service has a negative correlation with OTT platform's future value and a positive correlation with the platform's quality; while the pricing of the indirect communication service is positively correlated to platform's future value and negatively correlated with the platform quality.
\end{abstract}

Keywords: OTT, dynamic game, mobile operator, pricing strategy

\section{Introduction}

Today, we have evidently seen explosive spread of high-speed mobile Internet access which enables mobile subscribers to consume a variety of applications over the Internet. OTT (Over-The-Top) refers to voice, video and data services that arrive from a third party service provider (SP) and doesn't require any business or technology affiliations with the network operator (Southwell, 2011). These OTT services, such as WeChat in China, Line in Japan, and WhatsApp in the US are believed to have usurped the basic voice and SMS and cannibalized the revenues of mobile operators. For example, China Mobile, the largest mobile operator in China, whose SMS usage per subscriber declined by $7.5 \%$ in 2012 compared to that in 2011 (China Mobile Annual Report, 2012). Ovum, a consultancy specialized in telecommunications, estimated that OTT social messaging applications had cost worldwide mobile operators $\$ 13.9$ billion at the Year 2011 and this will rise to $\$ 54$ billion by 2016 (Doran, 2012). Peppard and Rylander (2006) argue that the value of mobile telecom industry has been moving from "bit transporting" to the content creating, from telecommunication networks to the Internet, from voice to information service. For mobile operators, competition with Internet enterprises would be more severe and tougher than that with their traditional counterparts.

Even though, mobile operators still enjoy some influences and control power over OTTs because OTT business relies on mobile-operator-owned network infrastructure to provide services. Furthermore, real-time OTT applications require frequent signaling and resetting linkage, thus take up a large part of signaling resource of the basic telecom networks. Therefore, mobile operators could technically monitor network usage and distinguish different OTT actors from each other (Bertin, 2012). From a market structure perspective, the mobile telecom market with the entry of OTT services is analogous to the traditional dual-channel distribution system. On one hand, mobile operators "sell" communication services such as SMS and voice directly to subscribers; on the other hand, they "wholesale" the network infrastructure to OTTs who rely on the network to distribute text, picture, video and voice to end users. In this case, what interests us is whether mobile operators should charge 
OTT applications an access fee since they are using their network assets, and if yes, then how?

Our paper builds on the literature of dual-channel and analyzes the emergence of OTT business in the telecom market. The dual-channel structure implies that the mobile operators might have two strategies facing the revenue decline caused by OTTs. First, they could charge OTT SPs a mobile Internet access fee as most manufactures do in traditional tangible product sectors. Second, they could cooperate with OTT SPs to form a joint venture and charge end users an OTT application usage fee as similar to a channel coordination strategy (Jeuland \& Shugan, 1983). Based on a dynamic gaming process, our model predicts that cooperation could lead to results where both mobile operators and OTT service providers receive larger profits. Besides, we analyze the optimal mobile Internet access price under non-cooperative condition and optimal OTT application access price under cooperative condition with all else as equal. Finally, we relax this condition and explore the dynamic coordinative pricing strategies for traditional telecoms services (the direct telecommunication service) and data service (the indirect telecommunication service) when the quality of OTT services is progressing.

\section{Literature Review}

The relevant literature to this paper is mainly on network competition in telecom market and dual-channel distribution system. Below we review the extant research on the two topics respectively.

\subsection{Competition in Telecom Market}

Telecommunications industry is characterized by a strong network effect, under which the value of telecommunication service to each user increases with the number of subscribers (Farrell \& Saloner, 1985; Shapiro \& Varian, 1999). To those products without network effect, innovating firms often use legal attacks or technological power to combat or deter imitation (Porter, 1980; Teece, 1986). However, in markets with strong network effect, innovators or the incumbent would benefit from licensing in generating a larger installed base (Sun et al., 2004). Extant research on networks competition in telecoms sector is focused on networks which have access to each other or are interconnected. Laffont et al. (1998) argue that in condition of unregulated competition between interconnected networks, a competitive equilibrium may not exist for large access charges or for large network substitutability, and that freely negotiated access charges may prevent effective competition in the mature phase of the industry. Bijl and Peitz (2009) analyze the effect of access regulation of PSTN networks on the adoption of VoIP (Voice over IP), in which they find that if the incumbent charges for call termination on the PSTN and VoIP networks use bill-and-keep, then a higher access price for call termination on the PSTN network would lead to a smaller customer base for VoIP company. Similar studies were conducted by Laffont and Tirole (2000), Armstrong (2002), Vogelsang (2003) and Peitz (2005).

This paper extends this stream of literature by addressing the competition and cooperation problem of two networks operating at different levels of network hierarchy. Specifically, mobile telecoms network and OTT network share the same physical network layer, however, operate independently (Bertin, 2012). For example, a phone call from a T-Mobile user or a VoIP user to an Orange user is fully natural, but receiving SMS originated from WeChat is not likely to happen if using a phone without WeChat app. Thus, architectural difference implies that the optimized competition-cooperation and pricing strategies may be quite different from the extant research.

\subsection{Dual-Channel Model in Telecom Market}

Mobile Internet has been evolving from a "walled garden" to a globally opened market with tens of thousands of applications based on IP technology, leaving mobile operators only responsible for data package distribution. In this situation, the telecom market structure is very similar to the traditional dual-channel distribution system. Extant research on dual-channel mainly focuses on channel selection, channel competition and coordination (Cai, 2010; Cattani, 2006; Chiang et al., 2003; Dumrongsir et al., 2008). For example, Chiang, Chajed and Hess (2003) argue that direct channel would help the manufacturer improve overall profitability by reducing the degree of inefficient price double marginalization and even retailer might benefit from the direct channel by a wholesale price reduction. However, the explanations of dual-channel in the traditional selling domains are not completely applicable to the telecommunications industry with the existence of OTT business.

The structure in telecom market with OTTs has its own characteristics. Specifically, (1) Mobile operators provide OTT companies with mobile Internet access and OTTs provide end users with the access to the OTT networks. However, "access", which means a right to join and use a network, is quite different from ownership transfer in traditional tangible product distribution. In this paper, in non-cooperative condition, we assume that mobile operators might charge OTT SPs a mobile Internet access fee based on the number of active subscribers on OTT network, and OTT SPs might charge (or subsidize) each user an OTT network access fee. (2) In telecom market, 
subscribers need to pay mobile operators for the amount of data being transferred. However, in traditional product distribution, it is not probable that consumers would pay manufactures an extra usage fee (see Figure 1). (3) Traditional retailors earn their profits by selling products with a higher price than the wholesale price. However, this might not be the case for the OTT business. What OTT SPs really concern is the future commercial value of the OTT platform after the accumulation of sufficient quantities of users, such as the value for from ads, e-business, traffic guidance and so on.

Based on these "new" characteristics, this paper aims to address the following research questions. How does the entry of OTT business affect the mobile operator's pricing strategy and profit? Whether or not should mobile operators charge OTT SPs the mobile Internet access fee? How could mobile operators make coordinative pricing with regard to mobile Internet access pricing, data traffic pricing and direct telecoms service pricing in order to maximize the profit?



Figure 1. Mobile telecommunications market structure in non-cooperative condition

\section{Model}

\subsection{Assumptions}

Considering the structure of mobile telecom market in Figure 1, we distinguish two alternative telecommunication services for consumers. One is the direct telecommunication service such as traditional SMS, MMS and voice with an average price of $P_{d}$, and the other is the indirect telecommunication service provided by OTT SPs with the data traffic price $P_{r}$, which consumers pay to the mobile operators, and $P_{d}>P_{r}$. We assume that the incumbent mobile operators have two alternative strategies to deal with the threats from OTT SPs, i.e., non-cooperative and cooperative strategies. Under non-cooperative strategy, mobile operator charges OTT a fixed mobile Internet access price $P_{w}$ per user on the OTT network, and OTT charges (or subsidizes) OTT subscribers an OTT network access price $P_{h}$ per user. Under cooperative strategy, mobile operator and OTT service provider charge each OTT network user $P_{c}$ as a whole price for accessing mobile Internet and OTT network. In the consumption decision process, consumers first consider whether to join OTT network or not, if yes then consider how to allocate the usage between the two telecommunication services. For simplicity, we investigate a simple structure, namely one mobile operator providing network infrastructure for one OTT SP who provides OTT service for consumers. We assume that all consumers are subscribed to the mobile operator's telecommunication network which means everyone could use the direct telecommunication service.

\subsection{Non-Cooperative Strategy Condition}

In this situation, three players play a three-stage dynamic game with complete information. At stage 1, mobile operator sets the price of $P_{w}$ with the objective of profit maximization. At stage 2, the OTT fixes the price of $P_{h}$ with the objective of profit maximization. Finally, at stage 3, consumers decide whether to join OTT network or not, and if yes they make further decision on the allocation of usage between direct and indirect telecommunication services.

\subsubsection{Consumer Preference Function}

According to backstepping reverse method in resolving dynamic games with complete information, we start with 
analyzing consumers' choice. With the emergence of OTT messaging applications, consumers should first decide whether to join the OTT networks or not. We assume the existence of a continuum of consumers. Each consumer is characterized by a parameter, $\theta \in[0,1]$, representing his/her preference for quality. Furthermore, we hold the premise that the utility function for a consumer depends on the quality of the service and his/her expected network effect. For a given $\theta$, under non-cooperative strategy condition, the utility function of joining OTT network is:

$$
E U_{r}=\theta q_{r}+\alpha q_{r} N_{r}-P_{h}
$$

where $q_{r}$ is the quality of OTT messaging service, $N_{r}$ represents the OTT network size, $\alpha$ measures the strength of the network effect. Furthermore, $\alpha$ is assumed to be less than 1 to ensure a downward-sloping demand function (Baake \& boom, 2001). For simplicity, no additional cost exists except the payment to OTT SP. An individual would buy the product if the resulting surplus is nonnegative. Define $\theta_{i}$ as the preference parameter of the consumer who is indifferent about adopting the OTT application, then:

$$
E U_{i r}=\theta_{i} q_{r}+\alpha q_{r} N_{r}-P_{h}=0
$$

Because those individuals who have a higher preference for quality, $\theta>\theta_{i}$, would like to to join OTT network, thus the total number of adopters is:

$$
n_{i r}=1-\theta_{i}=1-\frac{P_{h}-\alpha q_{r} N_{r}}{q_{r}}
$$

Consumers' expectation is fulfilled in the equilibrium, $n_{i r}=N_{r}$, thus we have:

$$
n_{\text {ir }}=\left(1-P_{h}\right) /(1-\alpha) q_{r}
$$

\subsubsection{Demand Function for Two Telecommunication Services}

We assume consumers' demand for telecommunication service is negatively related to service price. Especially, when service price is set to zero, the demand is averaged at 1 for each user. For those who have decided to join the OTT network, they need further to decide the allocation of usage between OTT application and traditional telecommunication service. We assume that the demand functions for the two alternative telecommunication services are as follows respectively:

$$
\begin{aligned}
& Q_{o d}=\frac{1}{2}\left[n_{i r}-P_{d}+\gamma\left(P_{r}-P_{d}\right)\right] \\
& Q_{o r}=\frac{1}{2}\left[n_{i r}-P_{r}+\gamma\left(P_{d}-P_{r}\right)\right]
\end{aligned}
$$

where $\gamma \in(0,1)$ is a measure of the degree of cross price sensitivity between the two services. As in McGuire and Staelin (1983), we restrict ourselves to those prices that lead to a nonnegative demand. Shubik and Levitan (1980) argue that it is consistent with individual utility maximization behavior that equation 2 and 3 both contain a term for own price and another term capturing the effect of the difference between own price and the price of the competitor. When the direct telecoms service price $P_{d}$, and data traffic price $P_{r}$ are set to zero, the demand for each of the two services equals to $n_{i r} / 2$ and the total demand for telecommunication service equals to $n_{i r}$.

\subsubsection{OTT's Profit Maximization Problem}

For OTT service provider, the profits are comprised by two parts: the current OTT network access revenue and expected future value of the platform. The current OTT network access revenue comes from the difference of OTT network access price $P_{h}$ and the mobile Internet access price $P_{w}$. Thus, the profit for this part is $\left(P_{w}-P_{h}\right) n_{i r}$. Expected future value of the platform means the future commercial value of the OTT platform after the accumulation of consumers. We assume that the present value of revenue that each subscriber brings in the future is $R$. Thus, the total present value of expected future value of the OTT platform is $R n_{\text {ir }}$. Hence the OTT's profit maximization problem is stated as follows:

$$
\max \left[R n_{i r}+\left(P_{h}-P_{w}\right) n_{i r}\right]
$$

\subsubsection{Mobile Operator' Profit Maximization Problem}

For mobile operator, under non-cooperative condition, the profits come from three parts: (1) profit from direct telecoms service sales $\left[P_{d}\left(1-n_{j r}-P_{d}\right)+P_{d} Q_{o d}\right],(2)$ profit from data traffic sales $P_{r} Q_{o r}$, and (3) profit from OTT's payment for mobile Internet access $n_{j r} P_{w}$. Hence, the mobile operator's profit maximization problem is 
stated as follows:

$$
\max \left[P_{d}\left(1-n_{i r}-P_{d}\right)+P_{d} Q_{o d}+P_{r} Q_{o r}+n_{i r} P_{w}\right]
$$

\subsubsection{Equilibrium Results for Non-Cooperative Strategy Condition}

As mobile operator sets the price $P_{w}$ before OTT SP sets the price $P_{h}$, OTT SP takes the price of $P_{w}$ as predetermined and tries to resolve the problem of equation 4 . By putting equation 1 into equation 4 and taking the derivative of equation 4 with respect to $P_{h}$, we find the optimal OTT network access price as shown in Table 1. Mobile operator anticipates OTT's action and tries to resolve the problem of equation 5. Then, we put the optimal $P_{h}$ into equation 5 and maximize it with respect to $P_{w}$. Now we find the optimal mobile Internet access price as shown in Table 1. By putting the optimal $P_{h}$ and $P_{w}$ back into equation 2,3,4 and 5, we are able to compute the demand and profit variables. Table 1 gives us a complete representation of the equilibrium outcomes for the dynamic gaming process.

Table 1. Equilibrium under non-cooperative strategy condition

\begin{tabular}{|c|c|}
\hline \multicolumn{2}{|l|}{ Demand } \\
\hline $\begin{array}{l}\text { Demand for direct } \\
\text { telecommunication service }\end{array}$ & $\frac{1}{16}\left(16-24 P_{d}+8 \gamma\left(-P_{d}+P_{r}\right)+\frac{-P_{d}+P_{r}+2\left(R+q_{r}\right)}{(-1+\alpha) q_{r}}\right)$ \\
\hline $\begin{array}{l}\text { Demand for indirect } \\
\text { telecommunication service }\end{array}$ & $\frac{1}{16}\left(8 \gamma\left(P_{d}-P_{r}\right)-8 P_{r}+\frac{P_{d}-P_{r}-2\left(R+q_{r}\right)}{(-1+\alpha) q_{r}}\right)$ \\
\hline \multicolumn{2}{|l|}{ Price } \\
\hline $\begin{array}{l}\text { Mobile Internet access } \\
\text { price }\end{array}$ & $\frac{R}{2}+\frac{P_{d}}{4}+\frac{q_{r}}{2}-\frac{P_{r}}{4}$ \\
\hline OTT network access Price & $\frac{P_{d}}{8}+\frac{3 q_{r}}{4}-\frac{R}{4}-\frac{P_{r}}{8}$ \\
\hline \multicolumn{2}{|l|}{ Profit } \\
\hline OTT’s profit & $-\frac{\left(-P_{d}+P_{r}+2\left(R+q_{r}\right)\right)^{2}}{64(-1+\alpha) q_{r}}$ \\
\hline Mobile operator's profit & $\begin{aligned}-\frac{1}{32(-1+\alpha) q_{r}}(4 & P_{r}\left(R+q_{r}\right)+4\left(R+q_{r}\right)^{2}+P_{r}^{2}\left(1+16(-1+\alpha)(1+\gamma) q_{r}\right) \\
+ & P_{d}^{2}\left(1+16(-1+\alpha)(3+\gamma) q_{r}\right) \\
& \left.-2 P_{d}\left(2\left(R+(-7+8 \alpha) q_{r}\right)+P_{r}\left(1+16(-1+\alpha) \gamma q_{r}\right)\right)\right)\end{aligned}$ \\
\hline $\begin{array}{l}\text { Total profits of OTT and } \\
\text { mobile operator }\end{array}$ & $\begin{aligned}-\frac{1}{64(-1+\alpha) q_{r}}\left(12 P_{r}\left(R+q_{r}\right)+12\left(R+q_{r}\right)^{2}+P_{r}^{2}\left(3+32(-1+\alpha)(1+\gamma) q_{r}\right)\right. \\
+P_{d}^{2}\left(3+32(-1+\alpha)(3+\gamma) q_{r}\right) \\
\left.-2 P_{d}\left(6 R+(-26+32 \alpha) q_{r}+P_{r}\left(3+32(-1+\alpha) \gamma q_{r}\right)\right)\right)\end{aligned}$ \\
\hline
\end{tabular}

We now consider the situation when mobile operator charges end users directly for using such service instead of charging OTT service providers. We argue that in this condition the equilibrium outcome is exactly the same as that in non-cooperative condition we have discussed above. Although mobile operators charge end users, OTT service providers could still charge (or subsidize) end users for joining OTT network and at the same time the game structure and objectives for OTT and mobile operator do not change. The only difference is in the payment process.

The equilibrium outcomes lead to the following propositions. 
PROPOSITION 1 When mobile operator chooses non-cooperative strategy and other things being equal, mobile operator would always be profitable by charging OTT SP the mobile Internet access fee.

In practice, $P_{d}>P_{r}$, thus the optimal mobile Internet access price which mobile operator charges OTT SP is always positive, that is, $\mathrm{P}_{\mathrm{w}}^{*}=\frac{\mathrm{R}}{2}+\frac{\mathrm{P}_{\mathrm{d}}}{4}+\frac{\mathrm{q}_{\mathrm{r}}}{2}-\frac{\mathrm{P}_{\mathrm{r}}}{4}>0$. The intuition is as follows. Consumers who join the OTT network need to allocate usage between direct and indirect telecommunication service. Essentially, both direct and indirect service are provided by mobile operator and both can fulfill the similar function, thus it is reasonable and profitable to charge an additional fixed access fee for the indirect telecommunication service which has a lower price.

PROPOSITION 2 When mobile operator chooses non-cooperative strategy and other things being equal, the optimal price mobile operator charges OTT SP and OTT SP charges end users is positively related to direct telecommunication service price and negatively related to data traffic price.

The intuition for proposition 2 is as follows. As stated in proposition 1, mobile operator would apply a two-part pricing strategy for the lower-usage-price OTT service. Other things being equal, if direct telecommunication service price increases, mobile operator would coordinately increase the price of the fixed part of OTT service, that is, mobile Internet access price. However, when mobile operator increases the data service fee, it would decrease the mobile Internet access price to counterbalance the unchanged direct telecommunication service price.

As to the OTT's optimal pricing strategy, it is positively correlated with direct telecommunication service price, and negatively with data traffic price, because the OTT network access fee has a linage effect with the price mobile operator charges OTT.

PROPOSITION 3 When mobile operator chooses non-cooperative strategy and other things being equal, the optimal mobile Internet access price is positively related to the future commercial value of OTT platform and the optimal price OTT SP charges end users is negatively related to future commercial value of OTT platform.

The intuition for proposition 3 is as follows. For OTT SP, the future value of OTT platform is the main concern. If the OTT platform is expected to obtain high future commercial value, OTT SP would rather sacrifice immediate interests and even subsidize end users to enlarge subscriber base. For mobile operator, it would set a high mobile Internet access price to extract the future value of OTT platform.

PROPOSITION 4 When mobile operator chooses non-cooperative strategy and other things being equal, OTT's profit is negatively related to direct telecommunication service price and positively related to data traffic price.

The proposition seems to be counterintuitive. The logics are as follows. When the direct telecommunication service price is decreased, the optimal mobile Internet access price $P_{w}^{*}$ and the optimal OTT network access price $P_{h}^{*}$ would decline, and the reduction range for $P_{w}^{*}$ is wider than that of $P_{h}^{*}$, causing increase of $\left(P_{h}-P_{w}\right)$. Besides, the decline of $P_{h}$ brings more OTT adopters. The two effects would increase the OTT profit. When the indirect telecommunication service price, or the data traffic price declines, both $P_{w}^{*}$ and $P_{h}^{*}$ would increase, and the addition range for $P_{w}^{*}$ is wider than that of $P_{h}^{*}$, causing decrease of $\left(P_{h}-P_{w}\right)$. Besides, the increase of $P_{h}$ prevents consumers from jointing OTT network. The two effects would reduce the OTT profit.

\subsection{Cooperative Strategy Condition}

In this situation, mobile operator chooses to form a vertically integrated alliance with OTT SP. The joint owner owns the whole channel system and perfect coordination exits. The joint owner would seek to maximize the sum of mobile operator and OTT profit. The total profits for joint owner consist of end users' payment for OTT network access and the future value of OTT platform. Two players play a two-stage dynamic game with complete information. At stage 1, the joint owner sets the the price of $P_{c}$ which represents end user's access fee for OTT network. At stage 2, consumers decide whether to join OTT network, and if yes they world further make the allocation decision between direct and indirect telecommunication services.

\subsubsection{Consumer Preference Function}

The basic assumptions are the same as in the non-cooperative strategy condition. First, consumers need to decide whether to join OTT network when they need to pay $P_{c}$ for joining OTT network. The reservation price is determined by the following utility function:

$$
E U_{r}=\theta q_{r}+\alpha q_{r} N_{r}-P_{c}
$$


Define $\theta_{j}$ as the preference parameter of the consumer who is indifferent about adopting the OTT application, then:

$$
E U_{j r}=\theta_{j} q_{r}+\alpha q_{r} N_{r}-P_{h}=0
$$

Because consumers with a higher preference for quality, $\theta>\theta_{j}$, will choose to join OTT network, the total number of adopters is:

$$
n_{j r}=1-\theta_{j}=1-\frac{P_{c}-\alpha q_{r} N_{r}}{q_{r}}
$$

Consumers' expectation is fulfilled in the equilibrium, $n_{j r}=N_{r}$, thus we have $n_{j r}=\frac{1-P_{c}}{(1-\alpha) q_{r}}$.

\subsubsection{Demand Function for Two Telecommunication Services}

As in non-cooperative strategy condition we assume that the demand functions for the two alternative telecommunication services are as follows:

$$
\begin{aligned}
& Q_{o d}=\frac{1}{2}\left[n_{j r}-P_{d}+\gamma\left(P_{r}-P_{d}\right)\right] \\
& Q_{o r}=\frac{1}{2}\left[n_{j r}-P_{r}+\gamma\left(P_{d}-P_{r}\right)\right]
\end{aligned}
$$

\subsubsection{Joint Owner's Profit Maximization Problem}

For joint owner, the overall profit consists of four parts: (1) profit from direct telecommunication service sales $\left[P_{d}\left(1-n_{j r}-P_{d}\right)+P_{d} Q_{o d}\right]$, (2) profit from data traffic sales $P_{r} Q_{o r}$, (3) profit from end users' payment for OTT network access $n_{j r} P_{c}$, (4) the present value of future OTT platform's commercial value $R n_{j r}$. Hence, the alliance's profit maximization problem is stated as follows:

$$
\max \left[P_{d}\left(1-n_{j r}-P_{d}\right)+P_{d} Q_{o d}+P_{r} Q_{o r}+n_{j r} P_{c}+R n_{j r}\right]
$$

\begin{tabular}{|c|c|}
\hline Demand & \\
\hline \multirow{3}{*}{$\begin{array}{l}\text { Demand for direct } \\
\text { telecommunication service }\end{array}$} & $(2+10)+1) D(1+1(110)$ \\
\hline & $\overline{8(-1+\alpha) q_{r}}\left(2\left(R+(-3+4 \alpha) q_{r}\right)+P_{r}\left(1+4(-1+\alpha) \gamma q_{r}\right)\right.$ \\
\hline & $\left.+P_{d}\left(-1-4(-1+\alpha)(3+\gamma) q_{r}\right)\right)$ \\
\hline $\begin{array}{l}\text { Demand for indirect } \\
\text { telecommunication service }\end{array}$ & $\frac{1}{8(-1+\alpha) q_{r}}\left(-2\left(R+q_{r}\right)+P_{d}\left(1+4(-1+\alpha) \gamma q_{r}\right)-P_{r}\left(1+4(-1+\alpha)(1+\gamma) q_{r}\right)\right)$ \\
\hline \multicolumn{2}{|l|}{ Price } \\
\hline OTT network access price & $P_{c}=\frac{P_{d}}{4}+\frac{q_{r}}{2}-\frac{R}{2}-\frac{P_{r}}{4}$ \\
\hline \multicolumn{2}{|l|}{ Profit } \\
\hline \multirow[t]{3}{*}{ Joint owner's total profit } & $-\frac{1}{16(-1+\alpha) q_{r}}\left(4 P_{r}\left(R+q_{r}\right)+4\left(R+q_{r}\right)^{2}+P_{r}^{2}\left(1+8(-1+\alpha)(1+\gamma) q_{r}\right)\right.$ \\
\hline & $+P_{d}^{2}\left(1+8(-1+\alpha)(3+\gamma) q_{r}\right)$ \\
\hline & $\left.-2 P_{d}\left(2\left(R+(-3+4 \alpha) q_{r}\right)+P_{r}\left(1+8(-1+\alpha) \gamma q_{r}\right)\right)\right)$ \\
\hline
\end{tabular}

\subsubsection{Equilibrium Results for Cooperative Strategy Condition}

After resolving this problem, the equilibrium outcomes are presented in Table 2.

Table 2. Equilibrium under Cooperative Strategy Condition 
PROPOSITION 5 When mobile operator chooses cooperative strategy and other things being equal, the access price of joining OTT network charged by joint owner is negatively related to the future value of OTT platform, positively related to direct telecommunication service price and negatively related to indirect telecommunication service price.

In cooperative strategy condition, joint owner would direct each member to act consistently with the objective of total profit maximization. Especially, mobile operator and OTT service provider share the future value of OTT platform. Thus, if the OTT platform has been expected to have a high future value, then joint owner would charge a low OTT network access price or even subsidize consumers to accumulate user base to an enough volume. The logic for the relation of OTT network access price and direct/indirect telecommunication is the same as what we have explained in proposition 2 .

PROPOSITION 6 Other things being equal, mobile operator and OTT SP would earn a higher total profit in cooperative strategy condition than that in non-cooperative strategy condition.

By comparing the total profit in cooperative and non-cooperative strategy condition, we have the difference of $\frac{3\left(-P_{d}+P_{r}+2\left(R+q_{r}\right)\right)^{2}}{64(1-\alpha) q_{r}}>0$, suggesting that cooperation could lead to results where both mobile operator and OTT SP receive larger profits.

PROPOSITION 7 When mobile operator chooses cooperative strategy and other things being equal, consumers pay less than that in non-cooperative strategy condition.

In non-cooperative strategy condition, end users pay OTT service provider the access fee of joining OTT network; while in cooperative condition, end users pay joint owner the OTT network access fee. Comparing the payment under the two conditions, we have the difference of $-\frac{P_{d}}{8}+\frac{q_{r}}{4}+\frac{R}{4}+\frac{P_{r}}{8}$. In general, $R \gg P_{d}>P_{r}$, thus $-\frac{P_{d}}{8}+\frac{q_{r}}{4}+\frac{R}{4}+\frac{P_{r}}{8}>0$.

\section{Mobile Operator's Dynamic Coordinative Pricing Strategy}

Above, we have discussed the tactic pricing strategy for both the mobile operator and OTT SP. For mobile operator, multiple prices could be simultaneously adjusted besides the mobile Internet access price. In this section, we seek to illustrate the mobile operator's optimal pricing on direct/indirect telecommunication service and mobile Internet access dynamically. After the emergence of OTT messaging application, its quality and user experience have been improving over time. Thus the quality of OTT could be seen as a proxy of time. We next show the dynamic trend of these optimal prices with the improving of OTT application quality.

By taking the derivative of mobile operator's profit function with respect to $P_{w}\left(P_{c}\right), P_{d}$, and $P_{r}$ in both non-cooperative and cooperative strategy condition, then solving the ternary equation, we could get the dynamic pricing strategy of $P_{w}\left(P_{c}\right), P_{d}$, and $P_{r}$ with the OTT quality improving.

4.1 Dynamic Pricing of Mobile Internet Access under Non-Cooperative Condition and Dynamic Pricing of OTT Access under Cooperative Condition

Figure 2 and Figure 3 describe the optimal prices of $P_{w}$ in non-cooperative condition and the optimal prices of $P_{c}$ in cooperative condition $(\alpha=0.5, \gamma=0.5)$. 


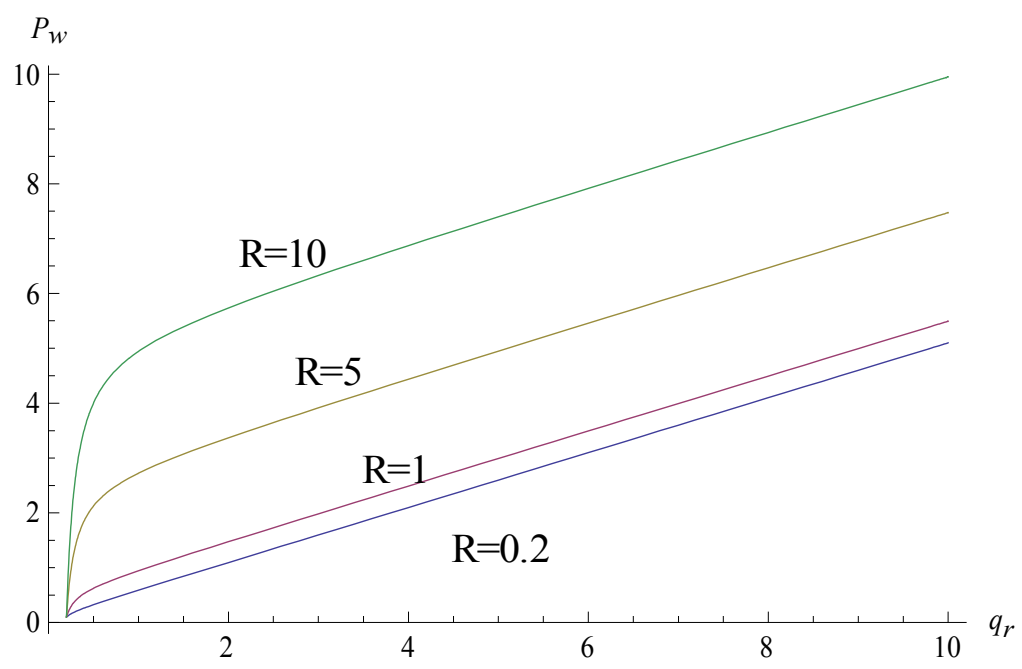

Figure 2. Optimal $P_{w}$ in non-cooperative condition

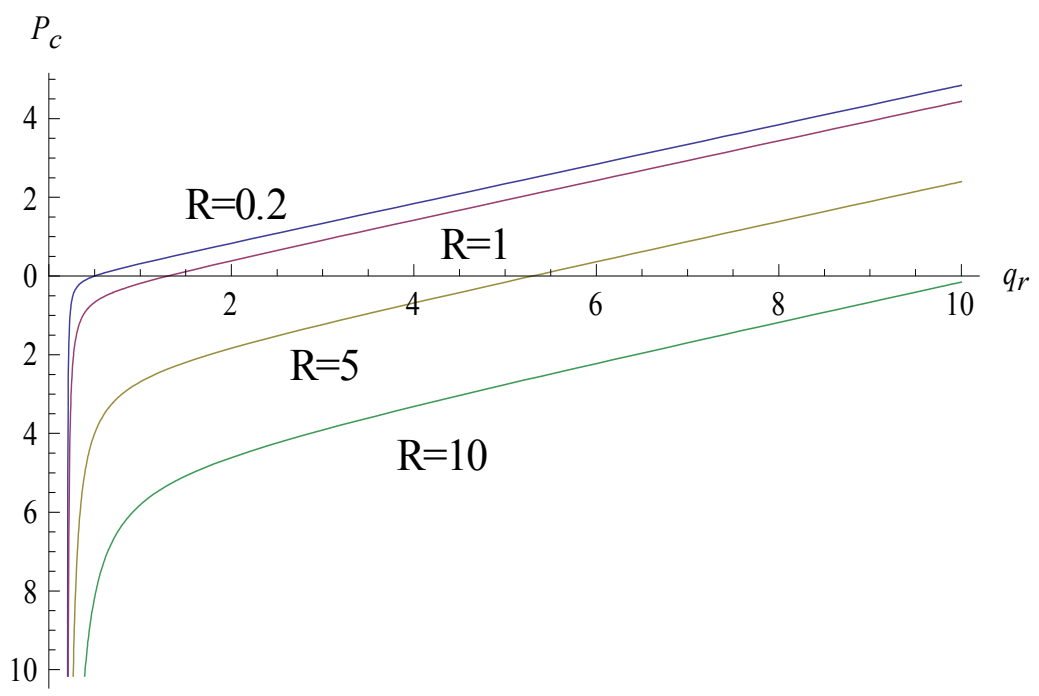

Figure 3. Optimal $P_{c}$ in cooperative condition

PROPOSITION 8 The optimal mobile Internet access price in non-cooperative strategy condition and the optimal OTT network access price in cooperative strategy condition are positively related to platform quality.

With the increase of OTT platform quality, the reservation price rises correspondingly. OTT SP in non-cooperative strategy condition or joint owner in cooperative strategy would benefit from increasing the OTT network access price. Especially, in non-cooperative strategy condition, the mobile operator would correspondingly charge OTT service provider a higher mobile Internet access fee.

4.2 Dynamic Pricing of Direct Telecommunication Service in Non-Cooperative and Cooperative Condition

Figure 4 and 5 describe the optimal direct telecommunication service prices in the condition of non-cooperative and cooperative strategy respectively and the representations lead to the following propositions. 


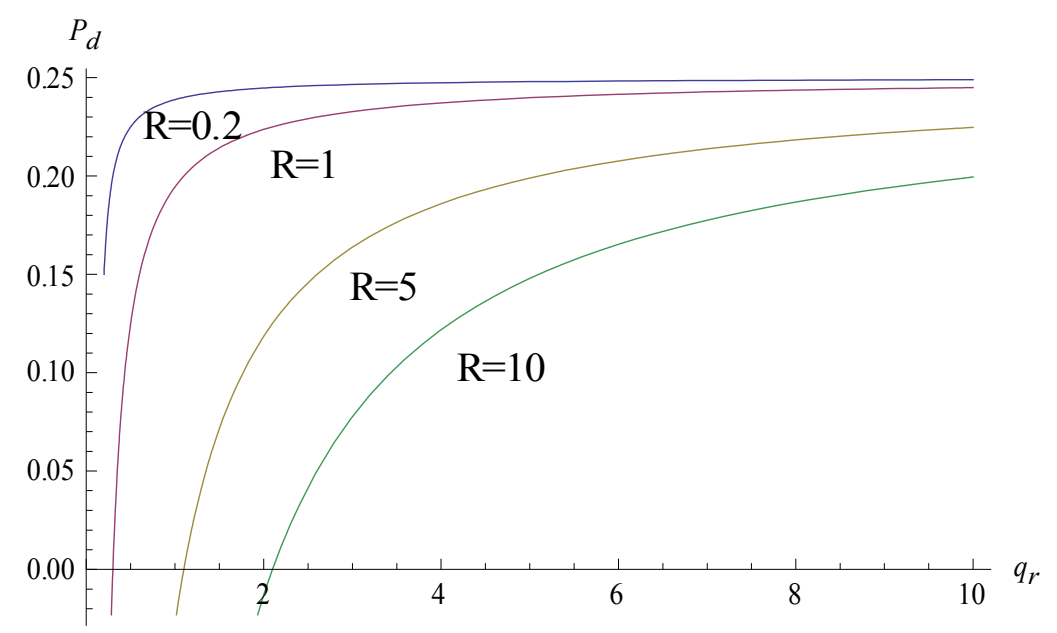

Figure 4. Optimal direct telecommunication service price in non-cooperative strategy condition

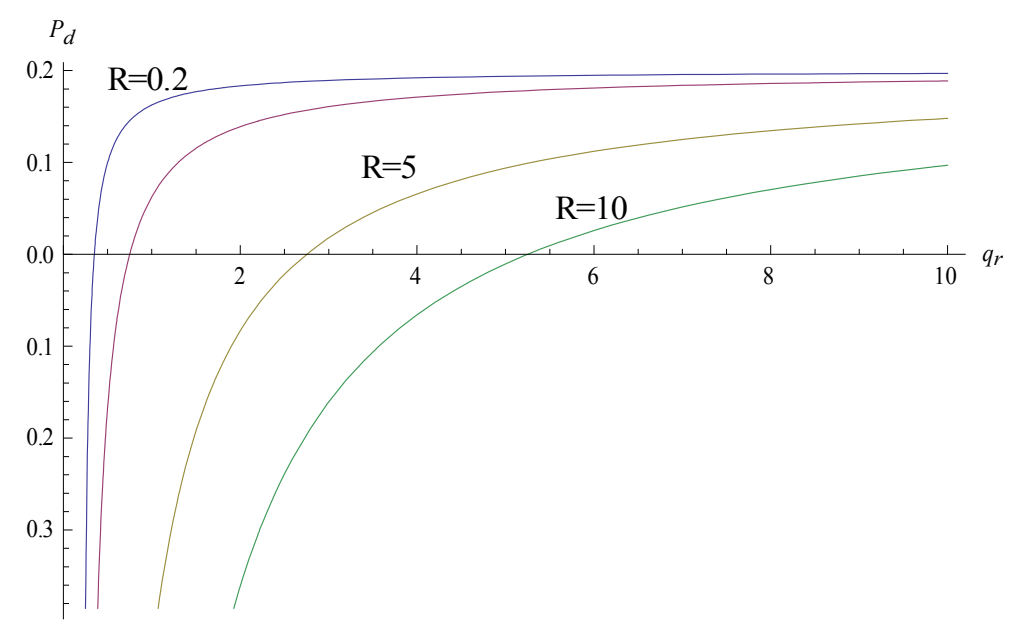

Figure 5. Optimal direct telecommunication service price in cooperative strategy condition

PROPOSITION 9 With the existence of OTT applications, the optimal direct telecommunication service price is positively related to OTT platform quality and becomes relatively stable when the OTT platform quality reaches a certain level.

PROPOSITION 10 The direct telecommunication service price is negatively related to OTT platform's future commercial value.

4.3 Dynamic Pricing of Indirect Telecommunication Service in Non-Cooperative and Cooperative Condition

Figure 6 and 7 describe the optimal indirect telecommunication service prices in non-cooperative and cooperative strategy conditions. 


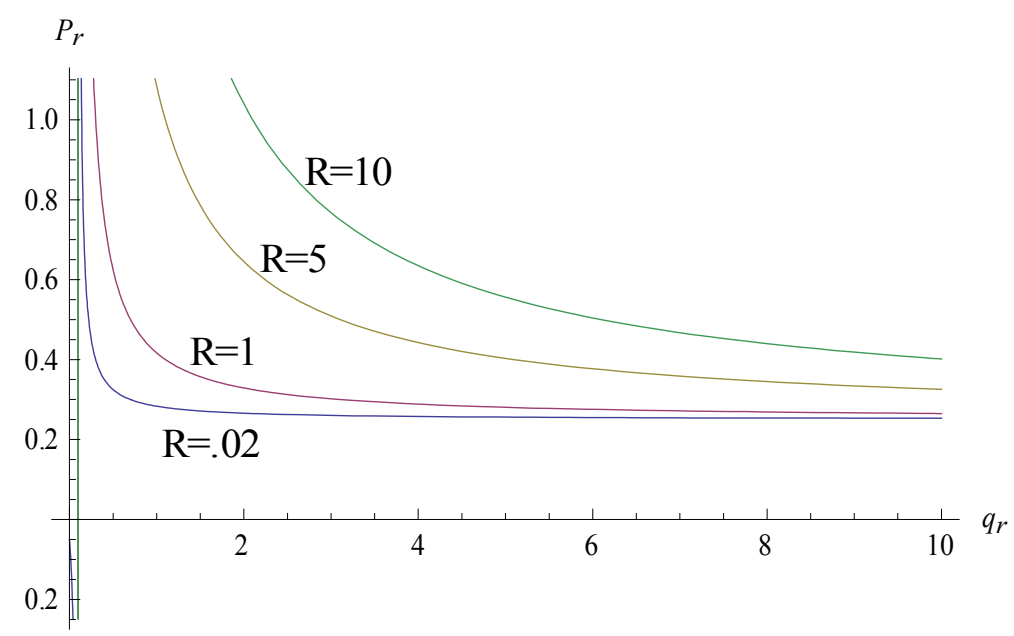

Figure 6. Optimal indirect telecommunication service price in non-cooperative strategy condition



Figure 7. Optimal indirect telecommunication service price in cooperative strategy condition

The results pertaining to the effect of platform quality are summarized in propositions 11 and 12 .

PROPOSITION 11 With the existence of OTT, the optimal indirect telecommunication service price is negatively related to OTT platform quality and become relatively stable when the OTT platform quality reaches a certain level.

PROPOSITION 12 The direct telecommunication service price is positively related to OTT platform's future commercial value.

\section{Case Verification}

Our theory predicts that the cooperation of mobile operator and OTT SP could bring higher overall profits than that in non-cooperative strategy condition. In practice, more and more mobile operators choose to cooperate with OTT SPs. Here are some examples: (1) in July 2012, KDDI, a telecommunication service operator in Japan, inked an agreement with Line in which KDDI agreed to add Line to the operator's "au Smart Pass" app promotion service. (2) in August 2012, Verizon enabled iPhone's facetime calls over a cellular connection without additional charge. (3) in November 2012, Orange announced to offer "Party Call," a "social calling" service on Facebook.

Besides these, a number of mobile operators cooperated with OTT messaging service providers to jointly promote OTT applications in the form of package plan. In November 2012, Reliance, India's fully integrated telecommunications service provider, launched first its kind prepaid plan "WhatsApp Plan" for all Reliance GSM subscribers in which Reliance GSM customers can enjoy unlimited usage of "WhatsApp" and Facebook across the country at a nominal fee of Rs. 16 per month without paying any extra data consumption charges. In 
February 2013, PCCW Mobile, a mobile communications service in Hong Kong, launched a WeChat data package through which PCCW Mobile subscribers could enjoy unlimited sending/receiving voice, video, photo and text messages, plus emoticons in Hong Kong via WeChat for just HK\$8 per month.

Essentially, in data package plan, mobile operators choose a cooperation strategy to charge end users OTT network access fee, and at the same time decrease the indirect telecommunication service price, or data traffic fee. This provides support for propositions 6 and 11 .

\section{General Discussion}

With the rapid evolving of mobile Internet, OTT business continuously launches innovative OTT applications. OTT messaging service has been accumulating hundreds of millions of subscribers because of low data traffic fee and diverse social features. For mobile operators, the emergence of OTT messaging service has been a big challenge since it has been substituting mobile operators' traditional telecommunication services such as SMS, MMS and voice to a great extent. How to response to the challenge is a great formative decision that mobile operators must make. This paper, form the perspective of dynamic gaming process, argues that mobile operator generally has two alternative strategies: non-cooperative and cooperative. The main conclusions are as follows.

(1) In non-cooperative strategy condition, mobile operator would always be profitable to charge OTT SP for mobile Internet access which is positively related to future commercial value and quality of OTT platform. For OTT SPs, they might charge or subsidize end users for OTT network access and the price is negatively related to OTT platform future commercial value and positively related to its quality.

(2) In cooperative strategy condition, the total profit for mobile operator and OTT SP is higher than that in non-cooperative strategy condition. In cooperative strategy condition, joint owner might charge or subsidize end users for OTT network access and the price is negatively related to OTT platform future commercial value and positively related to its quality.

(3) With the existence of OTT business, mobile operator's direct telecommunication service price is positively related to OTT platform quality and negatively related to OTT platform future commercial value. However, the indirect telecommunication service price, or the data traffic price, is negatively related to OTT platform quality and positively related to OTT platform future commercial value.

Currently, OTT business has exerted a substantial cannibalization effect on mobile operators' revenue. Mobile operators have been releasing signals to charge OTT services for additional mobile Internet access fee. However, we argue that for both mobile operators and OTT service providers, cooperation would always been a better choice. By cooperation, the two bodies would have a higher co-profit than that in non-cooperative condition. If mobile operators and OTT service providers set a reasonable share proportion, each side would be more profitable than that in non-cooperative condition.

For OTT service providers, no matter mobile service providers choose a non-cooperative or cooperative strategy, OTT platform future commercial value is a key factor in OTT's profit. Therefore, OTT service providers must find a clear business model after the accumulation of a large number of users. For mobile operators, they should first provide high-quality service for OTT by playing a good role of data pipe, strengthening the construction of physical network and improving internet access speed. At the same time, they could adopt a flexible pricing strategy by simultaneously adjusting direct and indirect telecommunication service price on the basis of evaluating the quality and future commercial value of OTT platform.

\section{Reference}

Armstrong, M. (2002). The theory of access pricing and interconnection. In M. Cave, S. Majumdar, \& I. Vogelsang (Eds.), Handbook of Telecommunications Economics. Amsterdam: North Holland.

Baake, P., \& Boom, A. (2001). Vertical product differentiation, network externalities, and compatibility decisions. $\begin{array}{lllll}\text { International Journal of Industrial Organization, } & \text { 19(1), }\end{array}$ http://dx.doi.org/10.1016/S0167-7187(99)00029-6

Bertin, E., Noel, C., \& Michel, L. (2011). A few myths about telco and OTT models. In Proceedings of 15th International Conference on Intelligence in Next Generation Networks (ICIN): "From Bits to Data, from Pipes to Clouds", Berlin, IEEE, 6-10. http://dx.doi.org/10.1109/icin.2011.6081106

Cai, G. G. (2010). Channel selection and coordination in dual-channel supply chains. Journal of Retailing, 86(1), 22-36. http://dx.doi.org/10.1016/j.jretai.2009.11.002

Cattani, K., Gilland, W., Heese, H. S., \& Swaminathan, J. (2006). Boiling frogs: pricing strategies for a manufacturer adding a direct channel that competes with the traditional channel. Production and Operations 
Management, 15(1), 40-56.

Chiang, W. Y. K., Chhajed, D., \& Hess, J. D. (2003). Direct marketing, indirect profits: a strategic analysis of dual-channel supply-chain design. Management Science, $49(1), \quad$ 1-20. http://dx.doi.org/10.1287/mnsc.49.1.1.12749

de Bijl, P. W., \& Peitz, M. (2009). Access regulation and the adoption of VoIP. Journal of Regulatory Economics, 35(2), 111-134. http://dx.doi.org/10.1007/s11149-008-9078-8

Doran, J. (2012). The OTT challenge \& operator response (close-up on TV \& Video). Ovum, (October 23).

Dumrongsiri, A., Fan, M., Jain, A., \& Moinzadeh, K. (2008). A supply chain model with direct and retail channels. European Journal of Operational Research, 187(3), 691-718. http://dx.doi.org/10.1016/j.ejor.2006.05.044

Farrell, J., \& Saloner, G. (1985). Standardization, compatibility, and innovation. The RAND Journal of Economics, 16(1), 70-83. http://dx.doi.org/10.2307/2555589

Jeuland, A. P., \& Shugan, S. M. (1983). Managing channel profits. Marketing Science, 2(3), 239-272. http://dx.doi.org/10.1287/mksc.2.3.239

Laffont, J. J., \& Tirole, J. (2001). Competition in telecommunications. Cambridge, MA: MIT Press.

Laffont, J. J., Rey, P., \& Tirole, J. (1998). Network competition: I. Overview and nondiscriminatory pricing. The RAND Journal of Economics, 1-37. http://dx.doi.org/10.2307/2555814

McGuire, T. W., \& Staelin, R. (1983). An industry equilibrium analysis of downstream vertical integration. Marketing Science, 2(2), 161-191. http://dx.doi.org/10.1287/mksc.2.2.161

Peitz, M. (2005). Asymmetric access price regulation in telecommunications markets. European Economic Review, 49(2), 341-358. http://dx.doi.org/10.1016/S0014-2921(03)00046-1

Peppard, J., \& Rylander, A. (2006). From value chain to value network: Insights for mobile operators. European Management Journal, 24(2), 128-141. http://dx.doi.org/10.1016/j.emj.2006.03.003

Porter, M. E. (1980). Competitive strategy. New York: Free Press.

Shapiro, C., \& Varian H. R. (1999). Information rules. Boston, MA: Harvard Business School Press.

Shubik, M., \& Levitan R. (1980). Market structure and behavior. Cambridge, MA: Harvard University Press. http://dx.doi.org/10.4159/harvard.9780674433403

Southwell, G. (2011). Win the OTT challenge, say goodbye to the pinwheel. CED, 37(4), 28-31.

Sun, B., Xie, J., \& Cao, H. H. (2004). Product strategy for innovators in markets with network effects. Marketing Science, 23(2), 243-254. http://dx.doi.org/10.1287/mksc.1040.0058

Teece, D. J. (1986). Profiting from technological innovation: Implications for integration, collaboration, licensing and public policy. Research Policy, 15(6), 285-305. http://dx.doi.org/10.1016/0048-7333(86)90027-2

Vogelsang, I. (2003). Price regulation of access to telecommunications networks. Journal of Economic Literature, 4l(3), 830-862. http://dx.doi.org/10.1257/jel.41.3.830

\section{Copyrights}

Copyright for this article is retained by the author(s), with first publication rights granted to the journal.

This is an open-access article distributed under the terms and conditions of the Creative Commons Attribution license (http://creativecommons.org/licenses/by/3.0/). 